\title{
Research on Adapting to QR Code by Auto-Repairing Students in Vocational High School
}

\author{
Chun-Hsin Chang \\ Department of Industrial Education, National Taiwan Normal University, Taipei, Taiwan \\ Email: antun@acrown.com.tw
}

Received January 2014

\begin{abstract}
QR code as a technology enhanced learning tool is prevailing not only in daily life, but also in education settings. The present study aims to explore the usage of QR code as a social medium in searching and learning profession knowledge of auto-repairing. The experiment contains 3 learning courses and 3 lessons for 155 students. Moreover, based on the theory of planned behavior, questionnaires are designed for students to fill out. A total of 153 copies are valid questionnaires. Confirmatory factor analysis is conducted while structural equation model is established. Research outcome indicates that Internet cognitive capacity correlates with hedonic and epistemic values, which reflect directly in learning attitudes of auto-repairing students using QR code. As sustaining intent of usage for $Q R$ code has to do with learning attitude of students, the study suggests that instructors should decrease complex contents of $Q R$ code before providing them to students for learning.
\end{abstract}

\section{Keywords}

QR Code, Hedonic Value, Utility Value, Learning Attitude, Intention

\section{Introduction}

Instruction of professional course for auto-repairing students in vocational high school tends to be conducted by instructors according to contents of textbooks. Great amount of photos are used to explain the operational principles [1]. Or, self-compiled electronic files are used as course contents instead of traditional course delivery. In the recent decades, teaching progression and teaching method are forced to change as teachers faced predicament [2]. Auto technology varies along with elapse of time, while teaching materials for auto technology in school fail to update and fall behind. How can students learn effectively? How can we help students learn dynamically in head? The key is not to accumulate knowledge but learn the procedure, which can enable us to transform knowledge into creative capacity required to make profits. That is, to empower students to apply knowledge [3]. Instructors for auto-repairing should emphasize innovative method to educate and learn, hence guide students to acquire capacity of multiple learning. 
During educational process, effectively use resources of Internet. Take advantage of this new educational environment to enhance educational effects, help students learn, and provide students with multiple means of learning [4]. Many relevant documents point out, combining information with instruction can indeed advance motivation and effectiveness for learning on the part of students [5]. Thus implement course integrating digital information and education should be able to help students learn, and elevate their learning effectiveness and satisfaction. Digital learning materials can indeed facilitate self learning for students.

As medium digitalization becomes reality, the study adopts QR code learning method to support traditional education. Since students enjoy the course of learning, they develop interest in professional course and become willing to learn actively. To be specific, the study aims to explore the process in which students adopts QR code, the relationship between Internet cognitive capacity of students with epistemic value of QR code, learning attitudes of students in learning QR code, and sustaining intent of usage for QR code on the part of student. Suggestions will be made according to research outcome to provide future reference for educators.

\section{Literature Review}

Development of Internet affords more options for educational methods. As Internet is far-reaching, it increases interest in learning for students [4]. Teaching via web gradually takes place of traditional teaching [6]. Whether using QR code in course on gasoline injection engine at vocational high school induces interest from students becoming a worthwhile subject of discussion.

\subsection{Theory of Planned Behavior}

Most researches on attitude and behavior are based on theory of reasoned action (TRA) and attitude model [7] which develops into theory of planned behavior [8]. Therefore, theory of planned behavior includes attitude, subjective rules and cognitive behavior control. Attitude and subjective rules come from theory of reasoned action. Cognitive behavior control is a newly added variable [9]. In theory of reasoned action, Fishbein \& Ajzen infer that intent affects action. Attitude and subjective rules to conduct specific behavior will affect theory model of behavior intent. Ajzen, 1988 brings up that behavior is not just up to attitude and subjective rules. It is also affected by control of self will power. Thus Ajzen [10] suggests that one is about to do conduct some behavior, only if he has capacity, resources and opportunity. Therefore, individual behavior intent is affected by attitude, subjective rules, and cognitive behavior control.

\subsection{Internet Cognitive Capacity}

Research confirms that cognitive accessibility of blog website by user will positively affect usage intent of user. And it further affects the actual degree of usage by user [11]. Exploration of fun factor in cognition for online games results in discovery that after students develop cognitive interest in experiences, it will have positive influence on their willingness of usage. The degree of influence tends to be high [12]. Many researchers find that degree of difficulty in usage affects user considerably. When user encounter barrier in using web, he will lose confidence and fail in web cognition. Cognitive failure can be defined as activity which ordinary people are able to accomplish ends with failure and operational mistake [13]. Cognitive failure refers to absent-mindedness and attention cannot focus in individual self reaction [14]. On the whole, web cognition capacity will directly affect learning condition and strength of hedonic value on the part of a learner.

\subsection{Experiencing Values: Hedonic and Epistemic}

Epistemic and economics have similar views on value. They consider consumption rational. Behavior is a goal-oriented tool [15]. Emphasizing epistemic value means consumer behavior is generally conducted after careful consideration, and it is efficient. In general, I define epistemic value as problem solution or behavior to fulfill some goal. Whether such behavior is beneficial to the future of learner, or able to resolve problem encountered, has to do with attitude of learning.

In contrast with epistemic value, hedonic value is more subjective and more personalized. Such value often involves fantasy, feelings, fun, experiences and great amount of significance in learning process [16]. Putting emphasis on hedonic value and needs often requires attaining excitement, confidence during the learning 
process.

Through aforementioned definition of hedonic value, and follow-up research on it, hedonic value gradually catches greater and greater attention and appears in researches on different circumstances. Hedonic value is the main drive to push user to apply new techniques [17]. By using structural equation model to proceed with model confirmation, the research outcome indicates that consumption behavior of hedonic value indeed produces affection on usage intent.

\subsection{Learning Attitude}

Good attitude of students should have specific learning goals, high interest in learning, aggressive and sustaining participation in learning, and problems overcome [18]. Aggressive learning attitude is the basis for ideals. It enables learner to lean towards fondness and participation. Passive learning attitude will let learner withdraw or reject learning. Therefore, different learning attitudes will affect learning results of students.

Learning attitude is teaching and learning process for a learner who keeps a sustaining and consistent inner reaction including interaction among cognition, emotion and behavior. It will further influence academic performance [19]. Attitude of engaging in all learning related activity is a psychological reaction and inclination developed against person, event and object of learning environment during the learning process [20]. Cheng Hsiu-ling [1] defines learning as a concept derived from attitude. It is based on contents of attitude, characteristics, and theory causing change. It emphasizes attitude of learning things. Learning attitude, on the other hand, is during learning related activity, learner develops positive or negative cognition and attitude towards things learned. Fishbein [7] also points out that "attitude” is positive or negative judgment harbored by individual towards some specific behavior.

\subsection{Intent of Sustaining Usage}

According to theory model brought up by Ajzen [8], behavior intent refers to subjective judgment whether one will be likely to conduct some behavior. It also reflects willingness to take action. He also suggests that individual behavior intent is the best variable to predict behavior. That is, strength of being engaged in specific behavior as self-motivated plan is called behavior intent [21]. Circumstances of the study continue to use intent to express habitual, continuous, active learning attitude developed by students during the process of learning QR code.

\subsection{Shaping of Research Framework}

From the aforementioned theory and relevant researches, it is known that according to Ajzen [8], theory of planned behavior model shapes main affected aspects resulting in web cognition capacity and its influence on hedonic and epistemic values. The study primarily draws on student applying QR code to learn auto-related knowledge. During the usage by students, degree of hedonic value has to do with epistemic value and learning attitude of QR code. Consequently, QR code learning attitude eventually draws attention to intent of sustaining usage. Therefore, the study brings up research framework as Figure 1.

According to aforementioned theory and research framework, the study brings up the following hypothesis while exploring sustaining usage intent relationship model and interaction among all factors:

H1: On web, cognitive capacity of students correlates with epistemic value.

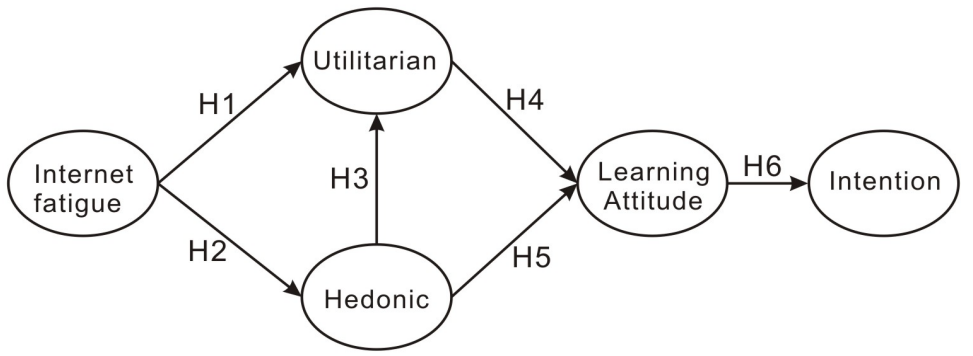

Figure 1. Framework model for the study. 
H2: On web, cognitive capacity of students correlates with hedonic value.

H3: Hedonic and epistemic values correlate for students.

H4: Epistemic value and learning attitude correlate for students.

H5: Hedonic value and learning attitude correlate for students.

H6: Learning attitude and intent of sustaining usage correlate for students.

\section{Research Design}

Current education requires application of new information technology to acquire knowledge. The study adopts smart phone or tablet PC to scan QR code via various sensors, then enter the website to begin learning. After experiment, students are requested to fill out questionnaire on degree of satisfaction for implementing QR code learning, in order to understand the influence and effectiveness of learning QR code.

\subsection{Application of QR Code Learning}

Rapid information transformation mechanism, inexpensive market price, easy operation for QR code, along with mobile communication facility and technology, enable information to circulate conveniently via multiple channels. Applied to public affairs, QR code can enhance validity, accuracy and effectiveness of confirmation operation. Applied to learning, it can let learning environment closer to reality and help learners to have immediate access to information to be acquired. Thus mobile learning is everywhere. Just as Cheng Chi-wen (2010) mentions, if the production process of QR code can combine with design in follow-up cross-platform learning, and further integrate with high technology mobile or tablet PC, it can indeed become a tool with immedate access to information. With advent of cloud-based technology, platform of life long learning community can be implemented.

\subsection{Research Steps}

The study aims at auto-repairing students in Taipei and New Taipei Cities who use smart phones or tablet computers to scan QR codes by various sensors (see Figure 2). After entering web pages, they start learning. Instructors give students learning checklists. Students fill out checklists according to materials on the web pages. Through contents of the learning list, instructors can control the progression of learning for students. Students learn QR code for two hours every week. They continue learning within four weeks. Meanwhile, surveys on learning satisfaction for QR code are to be filled out by students, in order to know the influence of learning QR code on course of auto injection engine.

\subsection{Example of QR Code Learning Contents-Air-Fuel Ratio Sensor}

This experiment teaching unit is on sensor for course of gasoline injection engine required in vocational high school. The web teaching databse connected to QR code is based on teaching material compiled according to Ministry of Educaiton course criteria for 2010 class outline on power machinery group. Figure 3 is excerpts of QR code teaching contents for the study.

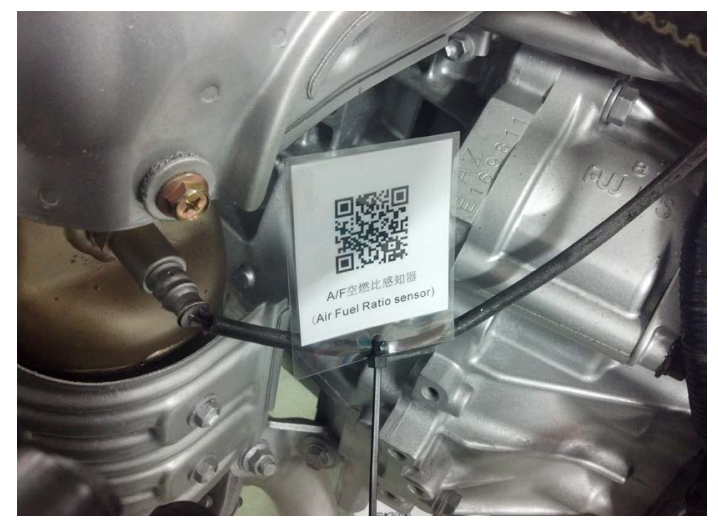

Figure 2. QR code is labeled on sensor. 


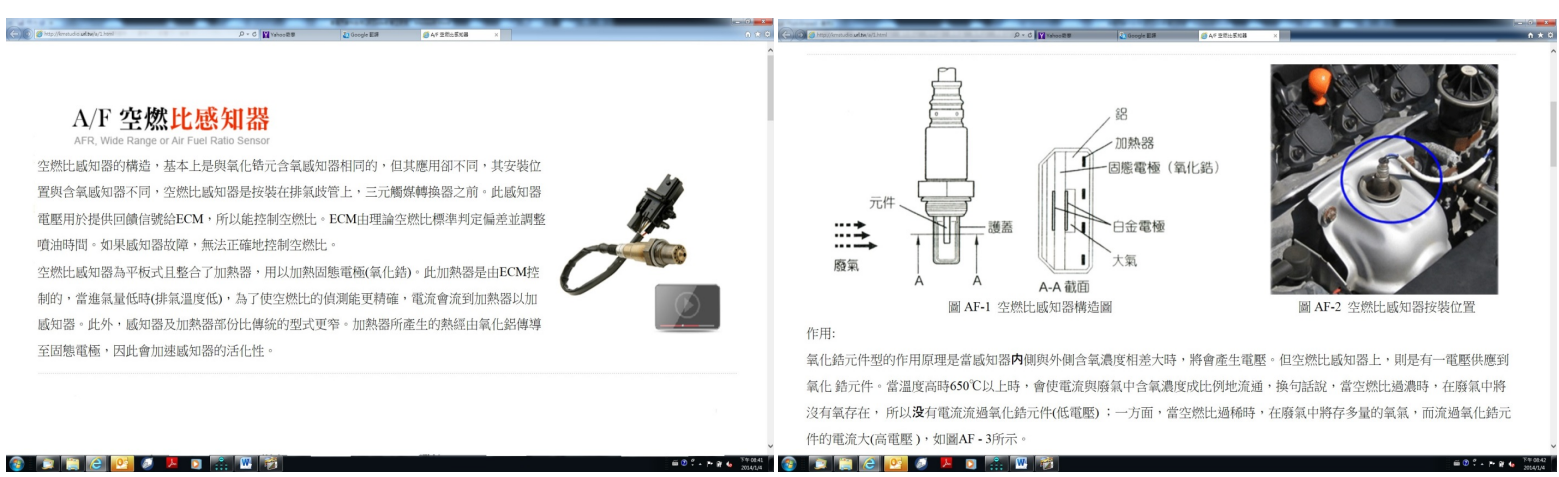

Figure 3. Example of QR code learning contents_-air-fuel ratio sensor.

\subsection{Research Object}

Objects of this experimental education are 75 senior auto-repairing students in Taipei City and 80 auto-repairing students in New Taipei City. A total of 155 students undertake experiment. A total of 155 Questionnaires for QR code learning satisfaction are distributed. Recovered questionnaires amount to 155 . Valid questionnaires amount to 153 . Among them, questionnaires filled out by students from Taipei City account for $49.9 \%$, while those by students from New Taipei City account for 50.1\%.

\section{Research Tools}

The study bases its research framework on collection of relevant theories and documents. It also refers to Government Official e-academy survey on condition of usage [22] and its structural contents. Keeping aspects of web cognition capacity, hedonic and epistemic values, and intent, it follows planned behavior theory and relevant theoretic basis by Ajzen [8], adds aspects on learning attitude, etc. By giving proper phrases and editing topics of its aspects, it enables design of questionnaire in accord with terminology of this study. There are 6 aspects and 37 questions. Through pre-test and post-check, it is discovered that credibility is too low. So questions are dereased to 24. Result of second test indicates that Cronbach's $\alpha$ value for questionnaire is 0.901 .

\section{Survey on QR Code Learning Satisfaction}

This survey aims to find out attitude and opinion on adopting QR code education for students in course on gasoline injection engine. The survey contains 6 aspects including 1) 3 questions on web cognition capacity; 2) 4 questions on hedonic value; 3) 6 questions on epistemic value; 4) 5 questions on learning attitude; 5) 6 questions on intent of sustaining usage. Measurement for all questions is based on Likert five-point scale.

\section{Research Outcome}

\subsection{Relevant Analysis}

The study draws on Cronbach's alpha credibility analysis to examine if questions in questionnaire are steady. The result indicates that the overall Cronbach's alpha coefficient for questionnaires is 0.901 . It means the general credibility for questionnaire is excellent [23].

From Figure 2, it is known according to Pearson relevant analysis coefficient that cognitive capacity correlates with hedonic value, cognitive capacity correlates with epistemic value, hedonic value correlates with epistemic value, learning attitude and intent of sustaining usage, hedonic value correlates with learning attitude and epistemic value, and learning attitude correlates with intent of sustaining usage.

\subsection{Appropriateness Analysis for Structural Equation Model}

The study confirms relevancy structure of learning satisfaction of QR code with SEM and AMOS (Analysis of Moment Structures) software package. The cause and result relationship of the six aspects of the study including learning anxiety, web cognition capacity, epistemic value, hedonic value, learning attitude and intent of sustain- 
ing usage can be found out in Table 1 and Figure 4. Therefore, measurement type degree of appropriateness indexes established by the study are as follows: RMSEA is $0.058(<0.08)$, NFI is $0.798(<0.9)$, IFI is 0.912 (>0.9), $\mathrm{CFI}$ is $0.908(>0.9)$, NNFI is $0.910(<0.9)$, RFI is $0.733(<0.9)$, GFI is $0.842(>0.8)$, AGFI is $0.808(>0.8)$.

\subsection{Path Analysis}

From Table 2 and Figure 4, it is found out that web cognition capacity and epistemic value appear obvious negative relationship. Its parameter estimate value is -0.132 . The more positive students have web cognition capacity towards QR code, the higher its epistemic value for QR code. The outcome supports Hypothesis 1. Web cognition capacity and hedonic value appear positive relationship. Its parameter estimate value is 0.147. The more students have web cognition capacity towards QR code, the higher is its hedonic value for QR code. The outcome supports Hypothesis 2.

Hedonic and epistemic values appear obvious positive relationship. Its parameter estimate value is 0.608 . The more positive students feel about hedonic value of QR code, the higher is its epistemic value for QR code. Its outcome supports Hypothesis 3. Epistemic and learning attitude appear obvious positive relationship. Its parameter estimate value is 0.283 . The more positive students feel about epistemic value of QR code, the higher is its learning attitude for QR code. This research outcome supports Hypothesis 4. Hedonic value and learning attitude appear obvious positive relationship. Its parameter estimate value is 0.658 . The more positive students feel about hedonic value of QR code, the higher is its learning attitude for QR code. The result supports Hypothesis 5. Learning attitude and intent of sustaining usage appear obvious positive relationship. Its parameter is 0.723 . The more positive students feel about learning attitude for QR code, the higher is its intent of sustaining usage for

Table 1. Relevancy coefficient.

\begin{tabular}{ccccc}
\hline & Internet cognitive & Utilitarian & Hedonic & Learning attitude \\
\hline Internet cognitive & 1 & & & \\
Utilitarian & 0.040 & 1 & 1 & 1 \\
Hedonic & 0.031 & $0.519^{* *}$ & $0.557^{* *}$ & $0.577^{* *}$ \\
Learning attitude & 0.125 & $0.516^{* *}$ & $0.712^{* *}$ & 1 \\
Intention & 0.009 & $0.548^{* *}$ & & \\
\hline
\end{tabular}

${ }^{*} p<0.05, \stackrel{* *}{p}<0.01$.

Table 2. Path parameter analysis.

\begin{tabular}{|c|c|c|c|c|}
\hline Path & Path parameter $\beta$ & $\mathrm{t}$ test & Aspect & $\mathrm{R}^{2}$ \\
\hline Internet cognitive $\rightarrow$ utilitarian & -0.132 & $-2.062^{*}$ & & \\
\hline Internet cognitive $\rightarrow$ hedonic & 0.147 & $2.022^{*}$ & Hedonic value & 0.022 \\
\hline Hedonic $\rightarrow$ utilitarian & 0.608 & $4.274^{* * *}$ & Epistemic value & 0.363 \\
\hline Utilitarian $\rightarrow$ learning attitude & 0.283 & $2.549^{*}$ & Learning attitude & 0.733 \\
\hline Learning attitude $\rightarrow$ intention & 0.723 & $7.029^{* * *}$ & Intent of & 0.523 \\
\hline
\end{tabular}

${ }^{*} p<0.05,{ }^{* *} p<0.01$.

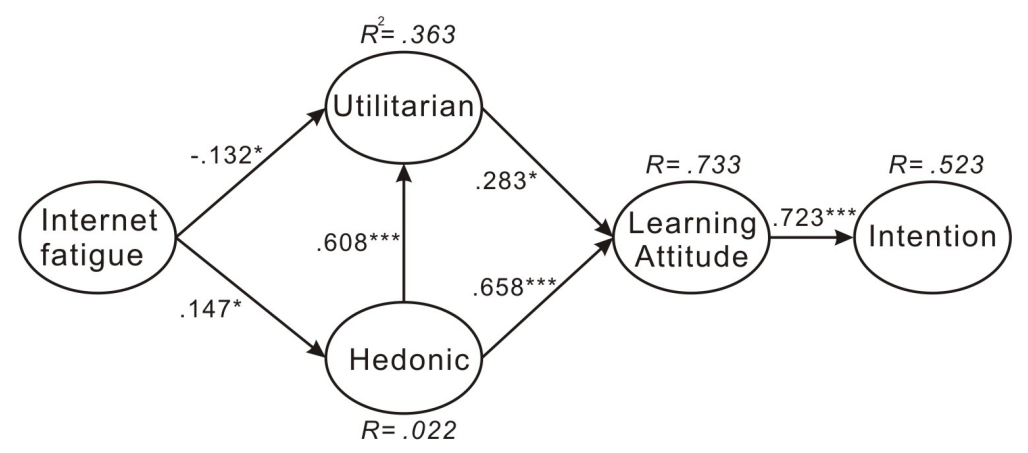

Figure 4. Confirmation research model. 
QR code. The result supports Hypothesis 6.

\section{Discussion}

Summarize the aforementioned structural model analysis; it is found out that epistemic value, hedonic value, learning attitude, and intent of sustaining usage directly influence learning effectiveness for students. It can be validly applied to learning behavior of QR code for auto-repairing students in vocational high school. The discovery proves the theories: 1) Intent of sustaining usage of QR code comes from learning attitude. 2) It proves the relationship among learning attitude, hedonic value and epistemic value. 3) It exemplifies that web cognition capacity, hedonic and epistemic values have interaction and mutual influence. To be specific, QR code learning model is rather important to learning intent for auto-repairing students.

Structural model analysis of the study results in the following outcome:

Learning QR code by auto-repairing students can be measured by theory of planned behaviour, and concept of object model, an attitude brought up by [7]. Learning attitude of auto-repairing students and intent of sustaining usage of QR code have obvious positive relationship. It means the more positive learning attitude the students have for QR code, the higher its intent of sustaining usage of QR code. The outcome is in accord with research results of Ajzen [8] and Fishbein [7] et al. The study also discovers that learning attitude of auto-repairing students for QR code has positive interaction with epistemic and hedonic values. It means they bear mutual influences among them.

The research outcome indicates that epistemic and hedonic values correlate with learning attitude. Research viewpoints of Bruner and Kumar [17]; Wang kai, Chen-yuan [24] are that hedonic value is the main drive to push user to use new technology. Combine hedonic value and technology reception model, hedonic value can thus be taken as outer incentive for technology reception model. Epistemic, hedonic values and learning attitude have obvious positive relationship. It means the higher epistemic and hedonic values are for auto-repairing students to use QR code, the higher is the learning attitude. It also means that epistemic and hedonic values are important factors of influencing learning attitude.

\section{Conclusion}

The current popularity of QR code application is noticeable in daily life print advertisement, introductions to library, zoo and botanical garden. It is also widely applied to word automated transmission, download of digital contents, websites rapid linking, identity differentiation and business dealing [25]. Many domestic scholars conduct researches on its academic and practical usage. However, there is no application of QR code to autorepairing professional education by researchers.

The study scans QR code via devices such as smart phone or tablet PC to allow students to proceed with learning. It is learned from research outcome that learning interest is affected by influence of positive or negative learning motivations of students [26]. During the research, student develops interest and curiosity towards learning QR code, then knowledge learned would carry epistemic value (for example, high grades in exam). Therefore, elevation in learning attitude enhances intent of sustaining usage for students. For both learning effectiveness and learning satisfaction, design of QR code learning has great help for au-repairing students.

\subsection{Research Contribution}

To sum up, outcome of the study suggests the following: First, web cognition capacity will affect hedonic value and learning anxiety during QR code learning. Design of the study comes from numerous discussions. It also designs web interface and learning contents easy to operate and read for students. Student will not experience learning anxiety and quit learning. Therefore, design of web interface and learning contents is very important. Secondly, many previous researches are limited to application of multimedia (such as film, animated art, and web online learning) to auto-repairing professional education. The study offers new technological, innovative learning method. That is, to learn contents of QR code through smart phone or tablet PC. During learning QR code, the students experience learning of interest and hedonic value. Therefore, epistemic value and attitude of learning QR code after learning are considerably elevated. The study establishes correlation among hedonic, epistemic values and learning attitude. At last, the study confirms significance of QR code to student learning. It strongly reflects the importance of learning attitude of QR code to intent of sustaining usage. It is concluded that 
hedonic value is inevitable to students during learning. Such innovative learning of QR code changes learning attitude of auto-repairing students towards professional course.

\subsection{Suggestion}

Instructors for vocation high school should take into account that student learning is not confined to traditional description and multimedia teaching methods. The research suggests that instructors for vocational high school ought to offer multiple learning environment and resources. In addition to cultivate professional capacity for students, teachers should help students generate passion and build confidence. With interesting topics to rouse curiosity on the part of students, so as to facilitate positive values students have towards professional skills. Via amiable atmosphere, students will be enabled to generate motivation of self-learning. QR code learning conducted with the help of supporting teaching methods is feasible. As contents of QR code learning is team work, it is inevitable to cooperate among peers to establish contents of QR code together. Besides, QR code learning is not just applicable to learning by auto-repairing students. It is also functional to learning by students in technology colleges and other courses in vocational high schools. If teachers offer students with QR code learning, they should pay attention to reduce complexity in QR code contents.

\subsection{Research Limitation and Future Research}

Limited to manpower, resources and time, the study scope of this research is confined to auto-repairing students in one engineering school at Taipei and New Taipei City each for individual experiment and research. Sample deviation is inevitable. Future research should enlarge sampling (to approximately 300 students) so as to increase research accuracy.

In structural model of the study, hedonic, epistemic values and learning attitude bear noticeable differences. Therefore, hedonic, epistemic values and learning attitude are interfering variable of considerable significance. In the future, different structural models can be applied to confirm if other aspects will affect learning attitude or intent of sustaining usage. For instance, research can be done on whether aspects such as contents satisfaction and interface design correlate with hedonic, epistemic values and learning attitude.

They are numerous researches on QR code learning, but there is none on learning in professional course at vocational high school. Future research can focus on practical training in individual subject to conduct experiment within a whole semester. Extend time of experiment to 12 weeks to increase reliability of research outcome.

\section{References}

[1] Cheng, H.-L. (2011) Research on Natural and Life Technology Learning Attitude and Learning Achievement for Elementary Students on Both Sides of the Taiwan Strait. Unpublished Thesis, Graduate School of Industrial Technology Education, National Kaohsiung Normal University, Kaohsiung.

[2] Shen, W.-Y. (2010) Research on Multimedia Education of Experimental Course on Injection Engine in Vocational High School. Unpublished Thesis, Graduate School of Industrial technology Education, National Kaohsiung Normal University, Kaohsiung.

[3] Tseng, C.-L. (2001) Turning Knowledge into Profit Innovation Is True Incentive. Symposium on "Era of Knowledge Economics—Role to Be Played by Colleges of Technology”. United Daily News, April 23, 23.

[4] Wen, T.-Y. (2011) Research on Factors Influencing Web Learning Effectiveness and Learning Satisfaction. Unpublished Thesis, Graduate School of Industrial Technology Education, National Kaohsiung Normal University, Kaohsiung.

[5] Wang, B.-C. (2007) Research on Information Technology Resolved in Educational Affection on Learning Effectiveness of Junior High School Students. Unpublished Thesis, Graduate School of Industrial Education, National Taiwan Normal University, Taipei.

[6] Wu, C.-Y. (2000) Comparison of Learning Effectiveness between Internet Education and Traditional Education—Exemplified by Education of Word 2000. Unpublished Thesis, Graduate School of Information Management, Tam Kang University, Taipei.

[7] Fishbein, M. (1967) Attitude and the Prediction of Behavior. In Martin.

[8] Ajzen, I. (1985) From Intentions to Action: A Theory of Planned Behavior. In: Kuhl, J. and Beckmann, J., Eds., Action-Control: From Cognition to Behavior, Springer-Verlag, Heidelberg, 11-39. 
http://dx.doi.org/10.1007/978-3-642-69746-3_2

[9] Ajzen, I. and Madden, T.J. (1986) Prediction of Goal-Directed Behavior: Attitudes, Intentions and Perceived Behavioral Control. Journal of Experimental Social Psychology, 22, 453-474. http://dx.doi.org/10.1016/0022-1031(86)90045-4

[10] Ajzen, I. (1989) Attitude Structure and Behavior. In Breckler, S.J. and Greenwald, A.G., Eds., Attitude Structure and Function, Lawrence Erlbaum, Hillsdale, 241-274.

[11] Li, K.-L. (2005) Research on Use Behavior for Blog Websites. Unpublished Thesis, Graduate School of Information Management, Chung-Yuan University, Miao-Li County.

[12] Wang, Y.-S. (2006) Exploration on Playful Factors Affect Online Games Cognition. Unpublished Thesis, Graduate School of Information Management, National Chang-Hua Normal University, Chang-Hua.

[13] Wallace, J.C., Kass, S.J. and Stanny, C.J. (2002) The Cognitive Failures Questionnaire Revisited: Dimensions and Correlates. The Journal of General Psychology, 129, 238-256. http://dx.doi.org/10.1080/00221300209602098

[14] Forster, S. and Lavie, N. (2007) High Perceptual Load Makes Everybody Equal Eliminating Individual Differences in Distractibility with Load. Psychological Science, 18, 377-381. http://dx.doi.org/10.1111/j.1467-9280.2007.01908.x

[15] Strahilevitz, M. and Myers, J. (1998) Donations to Charity as Purchase Incentives: How Well They Work May Depend on What You Are Trying to Sell. Journal of Consumer Research, 24, 434. http://dx.doi.org/10.1086/209519

[16] Holbrook, M.B. and Hirschman, E.C. (1982) The Experiential Aspects of Consumption: Consumer Fantasies, Feelings, and Fun. Journal of Consumer Research, 9, 132-140. http://dx.doi.org/10.1086/208906

[17] Bruner II, G.C. and Kumar, A. (2005) Explaining Consumer Acceptance of Handheld Internet Devices. Journal of Business Research, 58, 553-558. http://dx.doi.org/10.1016/j.jbusres.2003.08.002

[18] Chin, M.-C. (1992) Research on Relationship among High School Teacher Mindset of Administration, Student Inner and Outer Control Beliefs and Student Learning Habits and Attitudes. Education Psychology and Research, 15, 129172.

[19] Kin, W.-C. (2005) Research on Affection of Learning Attitudes for Students at Continued Education Program in Vocational High School. Master Thesis, Graduate School of Industrial Technology Education, National Kaohsiung Normal University, Kaohsiung.

[20] Fang, T.-N. (2006) Influence of Learning Performance in Learning Attitude and Learning Strategy of Professional Course to Students with Different Backgrounds-Exemplified by Two-Year College Students Majoring in Industrial Design. Unpublished Thesis, Graduate School of Design, Taiwan University of Technology, Taipei.

[21] Harrison, D.A., Mykytyn Jr., P.P. and Riemenschneider, C.K. (1997) Riemenschneider, Executive Decisions about Adoption of Information Technology in SmaBusiness: Theory and Empirical Tests. Information Systems Research, 8, 171-195. http://dx.doi.org/10.1287/isre.8.2.171

[22] Hong, J.-C., et al. (2013) Using a "Prediction-Observation-Explanation” Inquiry Model to Enhance Student Interest and Intention to Continue Science Learning Predicted by Their Internet Cognitive Failure. Computers \& Education, 72, 110-120. http://dx.doi.org/10.1016/j.compedu.2013.10.004

[23] Guieford, J.P. (1965) Fundamental Statistics in Psychology and Education.

[24] Wang, K. and Chang, C.-Y. (2012) Research on Integration of Attitude Measurement Models of Epistemic and Hedonic Values and Community Identity Establishment Social Websites. Information Management Journal.

[25] Ebner, M. (2008) QR Code-The Business Card of Tomorrow? Proceeding FH Science Day, Linz, 6 November 2008, 431-435.

[26] Pekrun, R., Goetz, T., Titz, W. and Perry, R.P. (2002) Academic Emotions in Students’ Self-Regulated Learning and Achievement: A Program of Qualitative and Quantitative Research. Educational Psychologist, 37, 91-105.

http://dx.doi.org/10.1207/S15326985EP3702_4 